\title{
O programa better work da oit e estratégias para a promoção do trabalho decente na cadeia produtiva do vestuário da cidade de Fortaleza: uma proposta de adaptação para a realidade local
}

\author{
The ilo better work program and strategies to promote decent work in the clothing \\ production chain in the city of Fortaleza: a proposal to adapt to local reality
}

\author{
Caroline Viriato Memoria* \\ Ana Virgínia Moreira Gomes ${ }^{* \star}$ \\ Anil Verma ${ }^{* * \star}$
}

\section{Resumo}

O trabalho forçado nas cadeias produtivas de vestuário é uma realidade internacional, nacional e local. A cidade de Fortaleza está entre as capitais do Brasil em que marcas de vestuário, inclusive locais, contratam força de trabalho de maneira precária para a produção de roupas. Em virtude disso, noartigoanalisam-semedidas de enfrentamento em busca de estratégias que promovamo trabalho decente na cadeia produtiva do vestuário.Dessa análise, a experiência do Better Work, da Organização Internacional do Trabalho - OIT se sobressai como um programa cujos elementos conceituais e procedimentais podem ser replicados, pois se baseia na preocupação com a reputação da empresa como um incentivo para promover melhoriasnas condições de trabalho na cadeia produtiva do vestuário. A capacidade de sanção do Estado brasileiro é baixa para enfrentar os casos em que o trabalho está sendo realizado em pequenas oficinas informais por artesãos de costura, ambientes por vezes protegidos pela garantia constitucional da inviolabilidade de domicílio. Logo, a prevenção e o combate nesses casos podem se dar mais pelo uso de medidas que comprometam a reputação da empresa. O objetivo da pesquisa é propor a utilização de elementos do programa Better Work para concepção de um modelo adaptado para a realidade das empresas da cadeia produtiva do vestuário de Fortaleza a melhorar a produtividade com base em boas condições de trabalho aos integrantes da cadeia. Para tanto, o estudo se desenvolve por meio de metodologiaqualitativa, de caráter descritivo, exploratório e propositivo, pautada em pesquisa empírica, bibliográfica e documental.

Palavras-chave: Trabalho Decente. Trabalho Forçado. Cadeia Produtiva de Vestuário. Programa Better Work. Organização Internacional do Trabalho. Reputação Empresarial.

\section{Abstract}

Forced labor in the clothing production chains is an international, national and local reality. The city of Fortaleza is among the capitals of Brazil where clothing brands, including local ones, hire workers precariously for the production of clothing. As a result, this paper analyses coping measures in search of strategies that promote decent work in the clothing production chain. From this analysis, the experience of the International Labor Organization - ILO Better Work stands out as a program whose conceptual and procedural elements can be replicated, as it is based on concern for the company's reputation as an incentive to promote improvements in working conditions in the clothing production chain. The sanction capacity of the Brazilian State is low against cases in which the work is being carried out in small informal workshops by sewing craftsmen, environments sometimes protected by the constitutional guarantee of inviolability of the home. Therefore, prevention and combat in these cases can be done more intensively through the measures that compromise the company's reputation. This research aims to propose the use of elements of the Better Work program to design a model adapted to the reality of companies in the productive chain of clothing in Fortaleza to improve productivity based on good working conditions for the workers in the production chain. So, the study is developed through qualitative methodology, of a descriptive, exploratory, and propositional character, based on empirical, bibliographic, and documentary research.

Keywords: Decent Work. Forced Work. Productivity Chain in Clothing. Better Work Program. International Labor Organization. Corporate Reputation.

* (9) Doutora em DireitoConstitucional/UNIFOR. Instituto Nacional de PesquisasEspaciaisem Natal/RN. Email: carolinememoria@hotmail.com.

** (9) Doutora em Direito do Trabalho/USP. Professor da Universidade de Fortaleza, Brasil. Email: avmgomes@unifor.br.

** (9) Doutor em Relações do Trabalho/MIT. Professor Emérito da Universidade de Toronto, Canadá. Email: anil.verma@rotman.utoronto.ca. 


\section{Introdução}

A globalização econômica mudou a forma de produção industrial no mundo. O modelo clássico de organização industrial verticalizada foi deixado de lado diante das rápidas transformações econômicas e tecnológicas. Com a maior liberalização comercial internacional e a revolução da tecnologia da informação, as empresas intensificaram a transformação em rede de suas operações internas e externas, e assim emergiram novos modelos de organizações, como o de redes de empresas.

O estabelecimento de relações com outras empresas e sua organização em redes de subcontratação e de terceirização (estratégias de gestão de mão de obra) contribuem para a formação de cadeias produtivas globais que materializam o novo modelo de produção e concretizam a mudança do paradigma de trabalho. Empresas multinacionais descentralizam sua produção na direção de países com ordenamentos trabalhistas mais frágeis, com o intuito de diminuir custos de produção, aumentar suas margens de lucro, ganhar competitividade no mercado globalizado e obter vantagem econômica no comércio internacional. No Brasil, também há empresas que pulverizam a produção, terceirizam e subcontratam trabalhadores e, para tanto, ignoram ou violam padrões laborais mínimos. A indústria de confecção do vestuário constitui um exemplo significativo desse novo padrão de relações de trabalho marcadas pela informalidade e flexibilidade e, por isso, foi a escolhida no recorte teórico deste artigo.

As redes de subcontratação e cadeias de terceirização; comumente observadas na produção do vestuário brasileiro; têm se revelado como um processo de deslocamento de atividades entre empresas, no bojo de uma nova divisão de trabalho, mas, sobretudo, como um mecanismo de transferência de riscos sobre a segurança, a saúde dos trabalhadores, vítimas de acidentes e doenças ocupacionais e como um instrumento de transferência de encargos trabalhistas, previdenciários e tributários das empresas tomadoras às subcontratadas ou terceirizadas.

Na cidade de Dhaka, em Bangladesh, no dia 24 de abril de 2013, desmoronou o prédio chamado Rana Plaza ${ }^{1}$ que abrigava trabalhadores da confecção de roupas para grandes marcas mundiais que levavam às últimas consequências a estratégia corporativa do fast fashion ${ }^{2}$. O desmoronamento do edifício ceifou a vida de 1.129 e feriu outros 2.500 trabalhadores que eram, majoritariamente, mulheres. $O$ episódio aguçou o debate sobre as condições de trabalho nas sweatshops ${ }^{3}$.

No Brasil, a produção do vestuário se dá, em geral, por meio de uma rede de subcontratação de grandes empresas confeccionistas, que descentraliza a produção em médias empresas ou micro e pequenas unidades produtivas, chegando, não raras vezes, ao trabalho em domicílio realizado por costureiras domiciliares (oficinas de costura), que formam cadeias produtivas locais também conhecidas pelo termo vulgar de "facções"

A Organização Internacional do Trabalho, OIT, exerce papel protagonista na prevenção e combate ao trabalho forçado nas cadeias produtivas globais de vestuário tanto através da aprovação de normas internacionais do trabalho; como é o caso da Resolução sobre Trabalho Decente nas Cadeias de Produção, adotada em 2016; quanto de programas de cooperação técnica com os Estados membros.

O vestuário que está à disposição no comércio esconde a realidade degradante de trabalhadores da cadeia produtiva desse setor da economia. A cidade de Fortaleza está entre as capitais do Brasil em que marcas de vestuário, inclusive locais, contratam força de trabalho de maneira precária para produção de roupas.

Dessa forma, este estudo tem como objetivo analisaras estratégias de promoção do trabalho decente na cadeia produtiva do vestuário em âmbitos nacional e internacional para propor uma política adequada à situação na cidade de Fortaleza. A pesquisa se encaixa na literatura que vem discutindo formas para assegurar o trabalho decente em razão da descentralização da produção.

O caso do Rana Plaza vem sendo discutido na literatura que trata do trabalho de cadeias de produção. Ver, por exemplo, Schuessler; Frenkel Wright (2018).

2 O novo modelo de produção de confecções, conhecido como fast fashion, é um conceito relativo à ideia de modarápida, que vemsendoutilizadocomopadrão para diversasmarcas e redes de varejo no vestuário (JACQUES, 2015, p.145)

3 Diferentemente do sistema fabril, em que a produção está centralizada em uma unidade de trabalho, os empregados são contratados diretamente pela empresa, cumprem o contrato de trabalho e diante controle completo da empresa sobre a produção e as condições de trabalho. Além disso, a residência do trabalhador é separada da planta fabril, o sistema de suor (Sweatshops) é baseado na subcontratação de serviços pulverizada em uma cadeia de micro e pequenas empresas - onde cada célula de trabalho é responsável pela confecção de uma parte da peça-, os locais de trabalho se confundem com as residências dos trabalhadores, as jornadas de trabalho são exaustivas, os salários miseráveis e as condições de trabalho são degradantes (GOMES; BEZERRA, 2018, p. 4).

4 O termo facção vem do francês façon, e significa feitio, criação, invenção, aparência, maneira de fazer (GOMES; BEZERRA, 2018, p. 7). 
O artigo usa um método qualitativo e empírico, que se efetiva por meio de pesquisa bibliográfica e documental, tanto no âmbito interno, quanto internacional, de caráter exploratório e propositivo, pelo método indutivo.

Pretende-se, na primeira seção do artigo, contextualizar como se dá o trabalho forçado na cadeia produtiva do vestuário nacional e internacional. A segunda seção contém a exposição sobre a experiência internacional do programa Better Work ${ }^{5}$, da OIT. Na seção seguinte, são analisadas medidas nacionais de enfrentamento ao trabalho escravo na cadeia produtiva do vestuário. E, na última seção, examinam-se estratégias de responsabilidade social empresarial na promoção do trabalho decente.

\section{Seção 1 - Os bastidores da cadeia produtiva do vestuário}

As redes são e serão os componentes fundamentais das organizações, haja vista que são capazes de formar-se e expandir-se por toda a economia global e, também, por contarem com o poder da informação propiciado pelo novo paradigma tecnológico. As principais fontes desse processo de transformação organizacional são: a globalização de mercados e insumos e a transformação tecnológica que força a contínua atualização das empresas (CASTELLS, 1999).

Segundo Jacques (2015), nos anos 1990, passou a revelar-se rentável a estratégia de fabricar produtos em países subdesenvolvidos e emergentes para rebaixar os custos de produção, por isso a maioria das empresas de vestuário desenha e comercializa seus produtos nos países desenvolvidos, mas subcontratam a produção aos fabricantes dos países em desenvolvimento e subdesenvolvidos. Nesse modelo de industrialização, as empresas que comercializam os produtos não os fabricam e integram uma nova classe de "fabricantes sem fábricas". A reorganização, e mesmo a instalação de empresas multinacionais em diferentes países, inauguraram uma nova divisão internacional do trabalho no setor.

Tanto nos países desenvolvidos, quanto nos países em desenvolvimento, os ganhos econômicos de se trabalhar em empresas da cadeia produtiva do vestuário não se traduzem necessariamente em bons empregos ou empregos estáveis por tempo indeterminado; e os números bem-sucedidos das exportações de empresas dessas redes de subcontratação podem estar ligados a uma deterioração significativa das condições de trabalho (ROSSI, LUINSTRA E PICKLES, 2014).

Nesse contexto, Meleu e Massaro (2017, p. 2093) destacam que as grandes corporações mercantis ganham força política e de domínio da vontade dos estados nacionais, determinando um fluxo de bens e capital que redesenhamos limites territoriais do mercado mundial, impactando de forma contundente a própria legislação trabalhista, que vem sendo desmantelada por decisões políticas.

Nesse cenário, vige o novo modelo de produção de confecções, conhecido como fast fashion, que congrega habilidade e velocidade para produzir as propostas apresentadas em feiras de vestuário e desfiles, para que assim o produto esteja na loja no momento em que uma tendência de consumo está no auge de sua força. A lógica por trás do modelo fast fashion, de prazos apertados, uso intensivo de mão de obra e baixos pagamentos, são fatores que, indiretamente, ocasionam a precarização do setor (JACQUES, 2015, p. 145). Em uma análise de dados coletados pelo Programa Better Work, Lupo e Verma (2020) identificam as pressões pela rapidez na entrega dos produtos da indústria do fast fashion, como um dos fatores mais importante na violação de normas referentes à limitação das horas de trabalho.

Dentro desse universo, Jacques (2015) realizou uma pesquisa de campo para analisar a cadeia produtiva da empresa Zara ${ }^{6}$ no Brasil, e verificou que a mesma estrutura-se em uma rede de empresas, com provedores diretos que se relacionam com empresas terceirizadas de serviços específicos (como tinturaria, por exemplo), e empresas de costuras enquanto oficinas têxteis subcontratadas. O pesquisador constatou que a lógica econômica e de gestão criada a partir da terceirização da Zara mascara o fato de que na realidade, tanto a provedora quanto as subcontratadas, funcionam exclusivamente para a multinacional. Logo, há relações trabalhistas formadas diretamente com a Zara encobertas pela rede de empresas.

5 O Programa Better Work foi criado pela OIT e a Corporação Financeira Internacional - um braço do sistema do Banco Mundial. O programa foca em empresas de confecção de vestuário em países em desenvolvimento que integram cadeias de produção global. O programa é inovador no sentido em que envolve fábricas e governos locais, além das empresas transnacionais compradoras, para promover trabalho decente. A Seção 2 irá examinar o programa. Ver também: <https://betterwork.org/>.

6 A Zara é uma das principais empresas de moda internacional. É uma das marcas pertencentes à Inditex, um dos maiores grupos de distribuição do mundo. Ver também: https://www.zara.com/. 
Se por um lado o estabelecimento de relações com outras empresas e a organização da força de trabalho em redes de subcontratação e terceirização permite as empresas ganharem dimensão global e contribuírem para a formação de cadeias produtivas globais e locais; por outro, favorecem a proliferação das formas de contratação mais inseguras (BEZERRA, 2017).

Esse é o "sistema do suor" (sweatshop), marcado por relações triangulares, nas quais existe mais de um tomador de serviços - o dono da confecção contratante e o dono do sweatshop - sendo até poligonais, inserindo outras empresas de confecção do vestuário ou ainda grandes varejistas têxteis de fast fashion. Essas se prevalecem do poder de direção para determinar, em uma relação de subcontratação, condições e métodos de trabalho, preços por peças confeccionadas, prazos de entrega, punições e outros comandos de direção e disciplina, subjugando o valor social do trabalho e a dignidade da pessoa humana do trabalhador (BIGNAMI, 2014).

Ao estudar as redes de subcontratação em Fortaleza (as chamadas "faç̧ões"), Bezerra (2017, p. 87) observou que "o trabalho em domicílio transfere à costureira não apenas a produção, mas também custos com energia, água, investimento em compra e manutenção de equipamentos, treinamento e qualificação profissional". A autora observou que as empresas de vestuário, por meio da subcontratação e terceirização, fragmentam algumas etapas do processo produtivo para "facções" e costureiras domiciliares, que realizam parte da produção sem contratos de trabalho com a contratante.

O setor do vestuário é marcado por grande mobilidade das empresas por diferentes regiões e/ou países e flexibilidade para a transferência da produção, bem como pela dificuldade dos trabalhadores em se organizarem coletivamente. Ademais, há ampla utilização da terceirização, informalidade, baixa remuneração, persistência de acidentes no trabalho (VEIGA; GALHERA, 2017). Dicken (2007) argumenta que a forma de organização da cadeia do vestuário oferece incentivos para a violação de direitos sociais e trabalhistas por conta da alta mobilidade e da pressão permanente por redução de custos.

Segundo Veiga e Galhera (2016) , as atividades se dão em pequenas oficinas de trabalhadores no setor de confecção do vestuário. Os trabalhos, assim realizados, são de difícil controle, pois as atividades se dão, via de regra, na casa dos trabalhadores, a qual goza de proteção constitucional da inviolabilidade de domicílio, o que dificulta o acesso da inspeção por agentes do Estado.

Compreendida a situação das redes de subcontratação que envolve as redes mundiais de confecções e, em nível nacional, as "facções" de costura, analisa-se na próxima seção o programa Better Work, da OIT, e o seu papel na promoção do trabalho decente.

\section{Seção 2 - O programa Better Work da OIT}

A OIT é a organização internacional especializada na garantia da justiça social, atuando de duas formas básicas: através da adoção de normas internacionais do trabalho e de programas de cooperação técnica com os Estados membros da organização para auxiliar no cumprimento de suas normas. Até o advento da globalização nos anos de 1970, o cenário de atuação da OIT era o da parceria com os Estados membros para que esses impusessem o cumprimento das condições básicas de trabalho. A globalização tornou esse cenário mais complexo ao permitir a desterritorialização da indústria e, consequentemente, a possibilidade da produção não mais se limitar ao âmbito de um Estado somente (GOMES, 2009). A OIT passou a se deparar, por um lado, com a situação de Estados menos desenvolvidos que buscam se beneficiar dos impactos positivos dessa descentralização, mas que, porém, não têm capacidade ou recursos para assegurar condições de trabalho decentes. $E$ por outro lado, com empresas sediadas em Estados desenvolvidos, que se beneficiam dessas cadeias produtivas, mas que não reconhecem sua responsabilidade pelas condições de trabalho dos trabalhadores envolvidos nessa cadeia.

A Resolução da OIT (OIT, 2016) relativa ao trabalho decente nas cadeias produtivas globais menciona falhas em todos os níveis dentro das cadeias, o que contribui para déficits de trabalho decente quanto às condições de trabalho; como nas áreas de segurança e saúde no trabalho; salários, tempo de trabalho e impacto sobre a relação de emprego e as proteções que ela pode oferecer. Essas falhas também contribuíram para minar os direitos trabalhistas, particularmente a liberdade de associação e negociação coletiva. O objetivo fixado pela Resolução tem como patamar os objetivos do trabalho decente. Conforme a OIT (2016), o trabalho decente tem como objetivo "[...] promover oportunidades para mulheres e homens alcançar o trabalho produtivo e decente, em condições de liberdade, equidade, segurança e dignidade". 
Embora Pessoa e Cabral (2015) lembrem que a falta de um poder sancionador da OIT comprometa a efetivação das suas normas que protegem condições mínimas de dignidade no trabalho, Vasconcelos (2001) ensina que disposições obedecidas apenas por medo de punição não são jurídicas. Esse entendimento foi acolhido por Machado Segundo (2016), ao defender que a sanção não é condição essencial para se reconhecer uma prescrição como jurídica. Para o autor, é inegável que a observância às regras deve se dar precipuamente por adesão espontânea e apenas acidentalmente por receio da sanção.

Nesse sistema, essa reputação é vista como um bem intangível valioso para empresas sérias no mundo todo (CONROY, 2007), assim, a perda de credibilidade de uma empresa pode ser vista como uma forma de punição. Historicamente, a OIT tem incentivado o cumprimento das normas trabalhistas prescritas em convenções por meio da persuasão moral, publicidade, shame sanctions ${ }^{7}$, diplomacia, diálogo e assistência técnica (EHRENBERG, 1996, apud HARPUR, 2011), porém sempre vinculando os Estados soberanos. O caso das cadeias produtiva, como visto, envolve diferentes atores, inclusive empresas que atuam globalmente. Esse foi o contexto que levou a OIT à criação do programa Better Work, que tem na manutenção da reputação um incentivo para a participação das empresas transnacionais.

O Better Work é um programa desenvolvido pela OIT, em colaboração com a Corporação Financeira Internacional, parte do grupo Banco Mundial. O programa reúne todos os níveis da indústria do vestuário, visando melhorar as condições de trabalho e o respeito dos direitos trabalhistas, bem como aumentar a competitividade das empresas do setor. Além de assessorar as empresas, o Better Work colabora com os governos para melhorar as leis trabalhistas, e com as marcas para garantir que o progresso seja sustentável. O programa também atua junto aos sindicatos para dar aos trabalhadores mais protagonismo. O Better Work presta assistência prática às empresas locais para ajudar os trabalhadores e empregadores no local de trabalho a se engajarem e cooperarem para resolverem seus próprios problemas. Por meio de pacotes de financiamento comercial, fornece incentivos financeiros na forma de taxas de juros preferenciais para as empresas que estão realizando melhorias nas condições de trabalho. Ademais, o programa possibilita que essas empresas locais tenham acesso a cadeias de produção com empresas compradoras, desde que respeitas as normas fundamentais do trabalho.

O Programa Better Work se estabelece em países ${ }^{8}$ nos quais os impactos negativos do trabalho nas redes de subcontratação da indústria de confecções são mais prováveis, fornece às principais marcas e varejistas relatórios de avaliações de conformidade de seus fornecedores, divulga publicamente as não conformidades (após aviso às empresas para fazerem as melhorias necessárias). Logo, a gestão da reputação da empresa torna-se um forte incentivo para promover melhorias. Um aspecto importante do programa no sistema da OIT é exatamente o envolvimento de empresas transnacionais, que escapam do sistema tradicional de supervisão internacional de cumprimento das normas internacionais do trabalho.

Uma avaliação de impacto contratada pela OIT, e conduzida pela Universidade Tufts (ILO, 2016) conclui que o programa Better Work tem um impacto significativo e positivo sobre as condições de trabalho em todos os países onde atua, com redução de práticas abusivas no local de trabalho, aumento do salário e redução das excessivashoras de trabalho, criando assim efeitos positivos fora das empresas para os trabalhadores e suas famílias. A pesquisa conclui também que foram decisivos para os resultados: a combinação de serviços que o Better Work fornece às fábricas ${ }^{9} \mathrm{e}$ o monitoramento do cumprimento das normas da OIT e da legislação nacional.

Reforçam a importância do Better Work os autores Rossi, Luinstra e Pickles (2014) ao afirmarem que melhorias sociais em indústrias de confecções (que são intensivas em mão de obra) podem ser alcançadas com baixo risco para os trabalhadores se iniciativas externas, como o programa Better Work, estiverem envolvidas para ajudar a certificar padrões de produção. Segundo Rossi (2015), dentro desse programa, "consultores empresariais" são recrutados localmente e treinados pela OIT, e conduzem seus deveres com base em um rigoroso código de ética, fundado na integridade, transparência, diplomacia e respeito.

A OIT manifesta-se em Relatório (ILO, 2017) no sentido de que seus instrumentos são valiosos para alcançar melhores condições de trabalho num mercado de trabalho globalizado, em que as novas tecnologias continuarão a

\footnotetext{
Medidas que podem afetar a reputação de empresas que submetam trabalhadores a condições análogas à de escravo, tais como a "Lista Suja do Trabalho Escravo", adotada no Brasil. Essa medida será tratada na Seção 3.

Bangladesh, Cambodja, Etiópia, Haiti, Indonésia, Jordânia, Nicarágua e Vietnã.

9 O Better Work ajuda a resolver disputas coletivas estabelecendo um Conselho de Arbitragem, fornecetreinamento, conscientizaostrabalhadoressobreosdireitostrabalhistas (ROSSI, 2015).
} 
transformar o local de trabalho. Mas, pondera que, para serem totalmente eficazes, os governos devem assegurar que os instrumentos da OIT sejam adequados às suas respectivas leis e práticas nacionais. Na esteira desse direcionamento, este estudo propõe que as bases do Better Work sejam replicadas no Brasil pelas instituições brasileiras, sobretudo na cidade de Fortaleza, cuja realidade de contratação degradante na cadeia do vestuário é constatada em pesquisa científica analisada na Seção anterior.

\section{Seção 3 - Medidas nacionais de enfrentamento ao trabalho escravo na produção do vestuário}

$\mathrm{Na}$ cadeia produtiva do vestuário há situações em que as condições precárias de trabalho são levadas ao extremo e são configurados casos de trabalho em condições análogas à escravidão, em afronta não somente às leis trabalhistas, como também ao Código Penal Brasileiro (Art. 149). Seja no campo, seja na cidade, o trabalho escravo quase sempre se integra, direta ou indiretamente, às formas mais novas do capitalismo e, ao mesmo tempo, aos modos mais antigos de exploração do trabalho humano (VIANA, 2006).

Veiga e Galhera (2016) descrevem episódio ocorrido no Estado de São Paulo, em 16 de agosto de 2011, no qual foram flagrados trabalhadores em condições de trabalho análogo ao de escravo, sob condições degradantes em que estavam presentes: cerceamento da liberdade, retenção de documentos por parte dos empregadores, tráfico de pessoas (trabalho realizado por imigrantes iludidos com promessas de um trabalho decente), contratações ilegais, jornadas exaustivas, servidão por dívida e trabalho infantil.

É dentro desse contexto que se inserem medidas levadas a efeito por atores particulares e públicos envolvidos com o problema. Por exemplo, a Portaria Interministerial $n^{\circ}$ 02/2015, que mantinha no âmbito do Ministério do Trabalho e do Ministério da Economia (a partir de 2019), o cadastro de empregadores que exploram o trabalho em condições análogas à de escravo, também chamado de "Lista Suja do Trabalho Escravo". ${ }^{10} \mathrm{~A}$ Portaria não trata de sanção legal, apenas torna público o resultado de um ato administrativo (VIANA, 2006). Segundo Bezerra (2017), essa medida identifica as empresas que utilizam mão de obra escrava e atua como um instrumento de inibição àquelas empresas preocupadas com sua reputação.

Para empresas que fazem uso direto ou indireto de trabalho escravo ou em condições análogas no Estado de São Paulo, está em vigor a Lei no 14.946, de 28 de janeiro de 2013 (SP, 2013), que dispõe sobre a cassação da inscrição no cadastro de contribuintes do Imposto sobre Operações Relativas à Circulação de Mercadorias e sobre Prestações de Serviços de Transporte Interestadual e Intermunicipal e de Comunicação - ICMS. Como consequência dessa medida, é possível citar o caso da empresa M5, detentora da marca M. Officer, que, em março de 2018, teve o registro do ICMS cassado após decisão do Tribunal Regional do Trabalho da $2^{a}$ Região de São Paulo ${ }^{11}$ e ficou impedida de exercer o mesmo ramo de atividade econômica ou abrir nova empresa no setor em São Paulo, por ter sido flagrada duas vezes submetendo trabalhadores e trabalhadoras a condições análogas à escravidão em oficinas de costura.

$\mathrm{Na}$ esteira dessas práticas punitivas, o Município de Fortaleza regulou, por meio da Lei $\mathrm{n}^{\circ} 10.631$, de 25 de outubro de 2017 (FORTALEZA, 2017), a cassação do Alvará de Funcionamento e demais licenças do município para qualquer empresa que faça uso de trabalho escravo ou em condições análogas à escravidão. Assim, não há registro de empresa que já tenha sido punida com a aplicação dessa lei.

Outra medida comprometida com o monitoramento das empresas que empregam mão de obra escrava é de propriedade de uma Organização Não Governamental - ONG e consiste num aplicativo chamado "Moda Livre" (online) que se propõe a ajudar os consumidores a comprarem roupas de forma consciente. Após a sua instalação gratuita, os usuários têm acesso ao conjunto de dados que mostram se a sua marca preferida de roupas foi ou não envolvida com denúncias de trabalho escravo na cadeia produtiva. O aplicativo também fornece informações sobre que tipos de iniciativas as marcas promovem para monitorar os seus fornecedores. São aplicados questionários junto às marcas varejistas das quais as empresas recebem notas de avaliação que equivalem a cores: se estiver envolvida e não monitorar a cadeia recebe cor vermelha, indicando ao usuário que se ele adquirir uma peça estará contribuindo para a violação da dignidade e dos direitos fundamentais dos trabalhadores.

10 O Cadastro de Empregadores que tenham submetido trabalhadores a condições análogas à de escravo recebe atualização periódica. Disponível em: <https://www.gov.br/trabalho/pt-br/inspecao/areas-de-atuacao/combate-ao-trabalho-escravo-e-analogo-ao-de-escravo $>$.

11 A decisão de segunda instância foi proferida no Processo número 00017795520145020054 . Ela confirmou a sentença que haviacondenadoaempresa por dumping social, que ocorrequandoumaempresa se beneficia dos custos baixosresultantes da precarização do trabalho para praticar a concorrênciadesleal. 
Para Bezerra (2017) , o enfrentamento ao trabalho escravo, a repressão ao trabalho forçado e o combate ao tráfico de pessoas devem ser objeto de políticas públicas que visem identificar, prevenir e combater violações aos direitos dos trabalhadores. Dentre essas políticas, Viana (2006) destaca o papel dos auditores-fiscais na estratégia de combate ao trabalho escravo, que mais do que apenas autuar empresas, fornecem subsídios para a atuação sucessiva do Ministério Público do Trabalho e da Justiça do Trabalho; e, ao reprimir, acabam prevenindo outras práticas. O autor destaca como outro relevante ator no combate à escravidão o Ministério Público do Trabalho, especialmente através das ações judiciais coletivas, bem como ao acolher denúncias, acompanhar blitzen, divulgar práticas e lutar na esfera política pela adoção de medidas no combate à escravidão.

Em estudo sobre a cadeia produtiva da indústria têxtil no Ceará, BARRETO (2021) observa, no entanto, que a atuação da inspeção do trabalho se dá de forma mais intensa nas empresas formais em Fortaleza em razão de dificuldades da própria inspeção do trabalho. Isso é um problema diante da alta taxa de informalidade das empresas nesse setor no estado. Conforme o autor, "de acordo com dados do Cadastro Geral de Empregados e Desempregados, CAGED, de 08/2020, 83,8\% (oitenta e três vírgula oito por cento) dessas empresas possuem todos os empregados informais e a média de empregados por empresa é de 2,37 (dois vírgula trinta e sete)" (Barreto, 2021, p. 94). Essa análise exemplifica a dificuldade de se enfrentar o problema somente com medidas punitivas.

Essas são algumas das medidas em vigor no país que lidam com casos extremos relacionados a empresas que cometem ilícito penal na relação de emprego. Para somar a esses esforços, sugere-se a atuação dessas instituições públicas e privadas, em sinergia com o escritório da OIT no Brasil, para formulação de um programa inspirado no Better Work, para enfrentamento do trabalho forçado nas cadeias produtivas nacionais do vestuário.

\section{Seção 4 - Responsabilidade Social Empresarial - RSE}

A fim de fundamentar a participação das empresas em programas como o Better Work, argumenta-se que o lucro das empresas não pode ser um fim em si mesmo; as empresas devem também responder à demanda por organizações socialmente responsáveis (DRUCKER, 2001). Stiglitz (2007, p. 432) pondera que, "para fazer a globalização funcionar, é necessário um regime econômico internacional em que o bem-estar dos países desenvolvidos e em desenvolvimento seja mais equilibrado". $O$ autor defende que a globalização deve funcionar não apenas para os ricos e poderosos, mas também para os mais pobres. O desenvolvimento econômico deve ocorrer de maneira sustentável, ou seja, sem degradar o meio ambiente e as relações de trabalho (KOKOL, MISAILIDIS, 2011).

Dentre os parâmetros das Organizações das Nações Unidas - ONU para as empresas protegerem, respeitarem e repararem violações a direitos humanos destaca-se o Princípio 13, segundo o qual a responsabilidade de respeitar os direitos humanos exige que as empresas:

A. Evitem que suas próprias atividades gerem impactos negativos sobre direitos humanos ou para estes contribuam, bem como enfrentem essas consequências quando vierem a ocorrer;

B. Busquem prevenir ou mitigar os impactos negativos sobre os direitos humanos, diretamente relacionados com operações, produtos ou serviços prestados por suas relações comerciais, inclusive quando não tenham contribuído para gerá-los (CONECTAS, 2021, p. 11).

Para Barbieri et al. (2010), a gestão empresarial sustentável envolve inovação, para melhoria dos processos produtivos, geração de valor na cadeia produtiva, obtenção de um consumo consciente e, por meio de um pósconsumo, com descarte correto dos produtos e embalagens, para atender aos objetivos que compõem o tripé da sustentabilidade (ambiental, social e econômico-financeiro).

Em relação à expansão da função empresarial para além do domínio econômico e das obrigações legais, Carroll (1991) concebeu modelo empírico (Pirâmide de Responsabilidade Corporativa) em que propõe uma estrutura em forma piramidal que incorpora quatro obrigações centrais da responsabilidade social da empresa RSE: responsabilidades econômicas (base), legais, éticas e filantrópicas ou discricionárias (topo). A organização da pirâmide se dá de acordo com as expectativas da sociedade para com a responsabilidade social de uma organização. Não se isola a performance social corporativa como algo completamente distinto da performance nos negócios (WOOD, 1991). Swanson (1995) propõe um modelo em que se reorienta o modelo de Performance Social Corporativa, de Wood, para um em que princípios de responsabilidade social empresarial se relacionem com responsividade e com resultados de comportamento empresarial. 
Essencialmente, a RSE se refere a obrigações da empresa direcionadas à sociedade, as quais vão além das obrigações econômicas e legais. Carroll e Shabana (2010) identificam aquelas obrigações como responsabilidades éticas e discricionárias/filantrópicas, que refletem a essência conceitual da RSE. As dimensões ética e moral das empresas também têm sido estudadas por Starke (1999), que se utilizou do modelo de desenvolvimento ético-empresarial de Eric Reidenbach e de Donald Robin ${ }^{1}$ para delinear o entendimento acerca da evolução moral da empresa, segundo o qual o último estágio não foi plenamente atingido, que é o do equilíbrio entre lucro e ética, haja vista que as empresas têm a responsabilidade social ainda em processo de aculturação.

Ao mapear as teorias de RSE mais relevantes, Garriga e Melé (2004) ponderam que as empresas podem contribuir para o bem comum de várias formas, tais como ao produzir riqueza, prover bens e serviços de um jeito eficiente e justo, ao mesmo tempo respeitando a dignidade e os direitos fundamentais inalienáveis dos indivíduos. Marrewijk e Werre (2003) complementam esse ponto de vista ao advertir que a sustentabilidade empresarial deve estar alinhada com os objetivos e estratégias organizacionais. Nessa perspectiva, em pesquisa empírica, os achados de Verma, Gomez e Oka (2015) convergiram no sentido de que a RSE não é apenas um investimento feito pelas empresas para melhorar as avaliações financeiras, mas que as empresas a usam para mitigar imprevistos e eventos danosos.

O'rourke (2006) pondera que muitas empresas multinacionais implementaram códigos de conduta se comprometendo com melhores condições de trabalho nas cadeias globais de suprimentos. Os códigos de conduta são documentos que reúnem um conjunto de princípios válidos para o relacionamento comercial da multinacional com os fornecedores, incluindo cláusulas sobre como tais princípios serão verificados e monitorados ao longo da cadeia produtiva.

Assim como o programa Better Work da OIT busca influenciar os compradores internacionais para práticas de compras mais responsáveis. Convém nesse momento destacar o papel primordial do consumidor na luta por um trabalho decente na cadeia produtiva do vestuário, tanto nacional quanto internacional. Logo, a formação de uma massa crítica voltada para o consumo responsável é mais um mecanismo que se soma aos demais para fazer pressão às empresas com a finalidade de melhorar as condições de trabalho no setor do vestuário.

Sobre as práticas conscientes, para que sejam difundidos mais amplamente os benefícios de melhores condições de trabalho, cada stakeholder ${ }^{12}$ exercepapel importante a desempenhar. Os ativistas e a mídia precisam expandir o escopo de sua atenção, não atentando apenas sobre os compradores de marca, mas também sobre os compradores sem marca, para que esses comecem a mudar o cálculo do custo-benefício e passem a se engajar mais com os fornecedores. Pois, os compradores precisam recompensar os fornecedores por uma melhor conformidade (compliance) $)^{13}$

Reforça-se, assim, a necessidade de adesão pelos stakeholders aos direitos fundamentais do trabalho, avançando em direção a uma responsabilidade social direcionada à criação de empregos de qualidade no setor de vestuário, com incremento de protocolos mínimos de trabalho decente.

\section{Conclusão}

Na perspectiva globalizante, e com os avanços tecnológicos, as empresas passaram a trabalhar em rede, possibilitando a subcontratação ilimitada de empresas na cadeia produtiva do vestuário, via de regra, para baixar custos. Essa rede de empresas "anônimas" dificulta a inspeção das condições de trabalho pelo Estado. Logo, a globalização possibilita que as empresas levem sua produção a cidades, regiões ou países com menor densidade sindical, menores salários, pouca ou nenhuma regulação trabalhista. No entanto, as atividades que exigem maior qualificação e agregam mais valor continuam concentradas nos países das matrizes das grandes corporações.

Nessa cadeia produtiva, o trabalho pode ser caracterizado pela flexibilidade, com redução de custos, apoio de governos locais, utilização de países em desenvolvimento - como plataformas de exportação -, haja vista a forte influência das grandes marcas do setor de vestuário nas decisões políticas locais. O elemento central que caracteriza a estrutura produtiva em cadeia diz respeito à formação de uma rede de atores econômicos a partir da subcontratação de tarefas e serviços. A ramificação da cadeia produtiva tem ocasionado a subcontratação de empresas têxteis com o uso, muitas vezes, de mão de obra escrava.

\footnotetext{
Stakeholder é toda pessoa ou "grupo de interesse" que é impactado pelas atividades de uma empresa.

Compliance é o dever da empresa de estar em conformidade com atos, normas e leis vigentes.
} 
Esse modelo de produção em rede de empresas provoca distanciamento dos varejistas em relação ao processo produtivo, e aos trabalhadores, e tem impactos negativos em matéria de direitos humanos e de trabalho decente. E não há dúvidas de que nessa e em outras circunstâncias, o comércio é gerado de forma ilegítima, não revertendo em qualquer benefício para quem produz a riqueza, e ainda prejudicando os concorrentes (dumping sociallit).

O artigo ocupou-se em apontar medidas adicionais à prevenção e ao combate que já é feito no Brasil, e para isso busca amparo na experiência internacional da Organização Internacional do Trabalho - OIT. Nesse aspecto, o artigo analisa uma iniciativa internacional que não depende de poder sancionador, mas que aposta na necessidade que toda empresa tem de gerenciar sua reputação. Trata-se do Programa da OIT chamado Better Work, cujas bases podem fundamentar iniciativas privadas ou públicas de enfrentamento às vulnerabilidades das cadeias produtivas de vestuário no Brasil.

O trabalho dá destaque também a medidas nacionais, tais como as leis municipais e estaduais que restringem o funcionamento de empresas em situação de irregularidade, seja pela cassação do alvará de funcionamento, seja pelo cancelamento do cadastro da empresa no ICMS. O artigo examina ainda a iniciativa pública da "Lista Suja" do trabalho escravo, que é uma medida reconhecida inclusive pela OIT. E apresenta, por fim, o aplicativo "Moda Livre", que é um instrumento prático que indica opções para um consumo responsável.

No Brasil, viu-se que a real capacidade de sanção do Estado é baixa para os casos em que o trabalho está sendo realizado em pequenas oficinas por artesãos de costura. Logo, a prevenção e o combate nesses casos devem se dar mais pelo uso de medidas que comprometam a reputação da empresa, no caso a que seja a principal contratante da cadeia produtiva. Daí se faz relevante o Estado e a sociedade civil se engajarem para que se realizem programas e políticas públicas que sejam efetivamente de Estado e não de governo. Conclui-se, portanto, que punições para empresas violadoras de padrões trabalhistas fundamentais são mais factíveis quando se tratam de casos extremos como o do trabalho escravo na cadeia de vestuário, principalmente por ser conduta tipificada como crime no Direito brasileiro.

Por fim, a prevenção e o combate são os desafios do trabalho decente nas cadeias produtivas mundiais e locais a serem enfrentados por lideranças sociais, políticas e econômicas, de modo a conferir maior inclusão social e proteção jurídica ao trabalhador. Tal prevenção ainda visa ocupações de qualidade, com remuneração adequada, exercício de atividades em condições de liberdade, possibilitando uma boa qualidade de vida e lazer, ofertando oportunidades para que homens e mulheres possam desfrutar de um trabalho produtivo em condições de igualdade, segurança e dignidade. Assim, empresas que subcontratam trabalhadores em condições indignas precisam redefinir seu papel social como agentes formadores de capital humano, haja vista que melhorar as condições de trabalho deve ser visto como um investimento, e não como um custo.

\section{Referências}

BARBIERI, José C. et al. Inovação e sustentabilidade: novos modelos e proposições. RAE - Revista de Administração de Empresas, São Paulo, v. 50, n. 2, p. 146-154, abr./jun. 2010.

BARRETO, Daniel Arêa Leão. Cadeia produtiva da indústria têxtil no Ceará: uma análise das políticas públicas garantidoras do trabalho decente. 2021. Dissertação (Mestrado em Direito Constitucional) - Programa de Mestrado em Direito Constitucional, Universidade de Fortaleza, Fortaleza, 2021.

BEZERRA, Lara Pinheiro. 0 trabalho decente e as redes de subcontratação: um estudo sobre as estratégias de proteção jurídica do trabalho precário na confecção do vestuário em Fortaleza. 2017. Dissertação (Mestrado em Direito Constitucional) - Programa de Pós-Graduação em Direito, Universidade de Fortaleza, Fortaleza, 2017.

BIGNAMI, Renato. Trabalho escravo na indústria da moda: o sistema do suor como expressão do tráfico de pessoas. Revista de Direito do Trabalho, São Paulo, v. 40, n.158, p.35-60, 2014.

14 Dumping social é a prática de concorrência desleal por empresa que visa reduzir os custos dos seus produtos utilizando-se de mão de obra mais barata, mediante afronta a direitos humanos, trabalhistas e previdenciários básicos. 
CARROLL, Archie B.; SHABANA, Kareem M. The business case for corporate social responsibility: a review of concepts, research and practice. International Journal of Management Reviews, [S.I.], v. 12, n. 1, p. 85-105, 2010. Disponível em: https://www.researchgate.net/publication/228118692_The_Business_Case_for_Corporate_ Social_Responsibility_A_Review_of_Concepts_Research_and_Practice. Acesso em: 02 jul. 2021.

CARROLL, Archie B. The pyramid of corporate social responsibility: toward the moral management of organizational stakeholders. Business Horizons, [S.I.], v. 34, n. 4, p. 39-48, july/aug. 1991. Disponível em: https://www.researchgate.net/publication/4883660_The_Pyramid_of_Corporate_Social_Responsibility_Toward_ the_Moral_Management_of_Organizational_Stakeholders. Acesso: 02 jul. 2021.

CASTELLS, Manuel. A sociedade em rede. São Paulo: Paz e Terra, 1999.

CONECTAS. Empresas e direitos humanos: parâmetros da ONU para proteger, respeitar e reparar Relatório final de John Ruggie. São Paulo: Conectas, 2012. Disponível em: https://www.socioambiental.org/ sites/blog.socioambiental.org/files/nsa/arquivos/conectas_principiosorientadoresruggie_mar20121.pdf. Acesso em: 02 jul. 2021.

CONROY, M. E. Branded: how the certification revolution is transforming global corporations. Gabriola Island, BC: New Society Publishers, 2007.

DICKEN, P. Global shift: mapping the changing contours of the world economy. Nova York: Guilford Press, 2007.

DRUCKER, Peter. O melhor de Peter Drucker: a administração. São Paulo: Nobel, 2001.

FORTALEZA. Lei 10.631, de 25 de outubro de 2017. Dispõe sobre a cassação do Alvará de Funcionamento e demais licenças do Município de Fortaleza para qualquer empresa que faça uso de trabalho escravo ou em condições análogas à escravidão. Câmara Municipal de Fortaleza: Fortaleza, 2017. Disponível em: https:// leismunicipais.com.br/CE/FORTALEZA/LEI-10631-2017-FORTALEZA-CE.pdf. Acesso em: 19 out. 2020.

GARRIGA, Elisabet; MELÉ, Domènec. Corporate social responsibility theories: mapping the territory. Journal of Business Ethics, [S.I.], v. 53, p. 51-71, 2004. Disponível em: https://docplayer.net/6924655-Corporate-socialresponsibility-theories-mapping-the-territory.html. Acesso em: 03 jul. 2021.

GOMES, Ana Virgínia Moreira; BEZERRA, Lara Pinheiro. A prática das sweatshops: uma realidade nas oficinas de costura brasileiras?. Revista da Faculdade de Direito do Sul de Minas, Pouso Alegre, v. 34, n. 1, p. 1-39, jan./jun. 2018.

GOMES, Ana Virginia Moreira. The effect of ILO's Declaration on Fundamental Principles and Rights at Work on the Evolution of Legal Policy in Brazil: an analysis of freedom of association. 2009. Dissertation (Master of Studies in Law) - Graduate Department of Law, University of Toronto, Toronto, 2009. Disponível em: https://tspace.library.utoronto.ca/bitstream/1807/18895/5/Gomes_Ana_VM_200911_LLM_thesis.pdf. Acesso em: 03 jul. 2021.

HARPUR, Paul. Better work: problems with exporting the better factories Cambodia project to Jordan, Lesotho, and Vietnam. Employee Relations Law Journal, [S.I.], v. 36, n. 4, p. 80-99, 2015. Disponível em: https:// papers.ssrn.com/sol3/papers.cfm?abstract_id=1804801. Acesso em: 03 jul. 2021.

INTERNATIONAL LABOUR ORGANIZATION. The future of work we want: a global dialogue. Geneva: ILO, 2017. Disponível em: https://www.ilo.org/wcmsp5/groups/public/---dgreports/---cabinet/documents/publication/ wcms_570282.pdf. Acesso em: 17 out. 2020.

JACQUES, Caroline da Graça. Trabalho decente e responsabilidade social empresarial nas cadeias produtivas globais: o modelo fast fashion em Portugal e no Brasil. Florianópolis. 2015. Tese (Doutorado em Sociologia Política) - Programa de Pós-Graduação em Sociologia Política, Universidade Federal de Santa Catarina, Florianópolis, 2015. 
KOKOL, Awdrey F.; MISAILIDIS, Mirta L. A agricultura canavieira no Brasil e os direitos fundamentais dos trabalhadores no novo contexto de sustentabilidade. Revista de Direitos e Garantias Fundamentais, Vitória, n. 10, p. 191-220, jul./dez. 2011.

LUPO, Luisa; VERMA, Anil. Labour standards compliance in the global garment supply chain: evidence from ILO's Better Work Program on the Role of Unions and Collective Bargaining. Geneva: International Labour Organization, july 2020. Disponível em: https://betterwork.org/portfolio/discussion-paper-37-labour-standardscompliance-in-the-global-garment-supply-chain/. Acesso em: 17 jun. 2021.

MACHADO SEGUNDO, Hugo de Brito. $O$ direito e sua ciência: uma introdução à epistemologia jurídica. São Paulo: Malheiros, 2016.

MARREWIJK, Marcel Van; WERRE, Marco. Multiple levels of corporate sustainability. Journal of Business Ethics, [S.I.], v. 44, p. 107-120, 2003. Disponivel em: https://www.researchgate.net/publication/225918057_ Multiple_Levels_of_Corporate_Sustainability. Acesso em: 03 jul. 2021.

MELEU, Marcelino; MASSARO, Alessandro Langlois. O papel da O.I.T. frente aos desafios do mercado. Rev. Direito e Práx., Rio de Janeiro, v. 8, n. 3, p. 2074-2105, 2017.

ORGANIZAÇÃO INTERNACIONAL DO TRABALHO. Trabalho decente. OIT, Brasília, [20-?] Disponível em: http://www.ilo.org/brasilia/temas/trabalho-decente/lang--pt/index.htm. Acesso em: 17 out. 2020.

ORGANIZAÇÃO INTERNACIONAL DO TRABALHO. Resolução relativa ao trabalho decente nas cadeias de suprimentos globais. Genebra: OIT, 2016. Disponível em: http://www.ilo.org/wcmsp5/groups/public/---ed_ norm/---relconf/documents/meetingdocument/wcms_497555.pdf. Acesso em: 17 out. 2020.

ORGANIZAÇÃO INTERNACIONAL DO TRABALHO. Normas Internacionais do Trabalho. OIT, Brasília, 2021. Disponível em: http://www.ilo.org/brasilia/temas/normas/lang--pt/index.htm. Acesso em: 17 jun. 2021.

ORGANIZAÇÃO DAS NAÇÕES UNIDAS. Transformando Nosso Mundo: a Agenda 2030 para o Desenvolvimento Sustentável. Rio de Janeiro: Centro de Informações das Nações Unidas para o Brasil, 2015. Disponível em: https://nacoesunidas.org/wp-content/uploads/2015/10/agenda2030-pt-br.pdf. Acesso em: 17 out. 2020.

O'ROURKE, D. Multi-stakeholder regulation: privatizing or socializing global labour standards? World Development, [S.I.], v. 34, n. 5, p. 899-918, 2006. Disponível em: https://www.researchgate.net/ publication/223631567_Multi-stakeholder_regulation_Privatizing_or_socializing_global_labor_standards. Acesso em: 03 jul. 2021.

OKA, Chikako. Accounting for the gaps in labour standard compliance: the case of Cambodia's garment Sector. European Journal of Development Research, [S.I.], v. 22, n. 1, p. 59-78, 2010. Disponível em: https://www. researchgate.net/publication/46526331_Accounting_for_the_Gaps_in_Labour_Standard_Compliance_The_ Role_of_Reputation-Conscious_Buyers_in_the_Cambodian_Garment_Industry. Acesso em: 03 jul. 2021.

PESSOA, Anna Stephanie de Brito Veiga; CABRAL, Monara Michelly de Oliveira. O desafio da concretização dos direitos humanos do trabalhador: uma leitura da implementação da cláusula social no âmbito da OMC e o constitucionalismo multinível. Cadernos da Escola de Direito e Relações Internacionais, Curitiba, v. 1, n. 17, p. 434-455, 04 mar. 2015. Disponível em: https://portaldeperiodicos.unibrasil.com.br/index.php/cadernosdireito/ article/view/2982/2552. Acesso em: 17 out. 2020.

ROSSI, Arianna. Better work: harnessing incentives and influencing policy to strengthen labour standards compliance in global production networks. Cambridge Journal of Regions, Economy and Society, Oxford, v. 8, n. 33, p. 505-520, 2015. Disponível em: https://pt.booksc.org/book/47085882/5085fa. Acesso em: 03 jul. 2021.

ROSSI, Arianna; AMY, Luinstra; PICKLES, John. Towards better work: understanding labour in apparel global value chains. Geneva: International Labour Organization; Palgrave Macmillan, 2014. 
SCHUESSLER, E.; FRENKEL, S. J.; WRIGHT, C. F. Governance of labor standards in Australian and German garment supply chains: the impact of Rana Plaza. ILR Review, New York, v. 72, n. 3, p. 552-579, 2018. Disponível em: https://journals.sagepub.com/doi/full/10.1177/0019793918771360. Acesso em: 03 jul. 2021.

SÃO PAULO. Lei $\mathbf{n}^{\circ}$ 14.946, de 28 de janeiro de 2013. Dispõe sobre a cassação da inscrição no cadastro de contribuintes do Imposto sobre Operações Relativas à Circulação de Mercadorias e sobre Prestações de Serviços de Transporte Interestadual e Intermunicipal e de Comunicação - ICMS, de qualquer empresa que faça uso direto ou indireto de trabalho escravo ou em condições análogas. São Paulo: Assembléia Legislativa do Estado de São Paulo, 2013. Disponível em: https://www.al.sp.gov.br/repositorio/legislacao/lei/2013/lei-1494628.01.2013.html. Acesso em: 17 out. 2020.

STARKE, Linda. As cinco etapas da evolução moral da empresa. In: RAY, Michael; RINZLER, Alan (org.). 0 novo paradigma nos negócios. Tradução: Gilson Cesar Cardoso de Sousa. São Paulo: Cultrix, 1999, p. 186199.

STIGLITZ, Joseph E. Globalização: como dar certo. São Paulo: Companhia das Letras, 2007.

SWANSON, Diane L. Toward an integrative theory of business and society: a research strategy for corporate social performance. The Academy of Management Review, New York, v. 24, n. 3, p. 506-521, 1999.

VASCONCELOS, Arnaldo. Direito e força: uma visão pluridimensional da coação jurídica. São Paulo: Dialética, 2001.

VEIGA, J. P.; GALHERA, K. Entre o lar e a 'fábrica': trabalhadoras bolivianas da costura na cidade de São Paulo. In: FIGUEIRA, R. R.; PRADO, A. A.; GALVÃO, E. M. (org.). Discussões contemporâneas sobre trabalho escravo: teoria e pesquisa. Rio de Janeiro: Mauad, 2016. p. 119-145.

VERMA, Anil; GOMEZ, Rafael; CHIKAKO Oka. Why do firms engage in corporate social responsibility?: a test of the damage mitigation hypothesis using evidence from publicly-listed firms in Canada. In: WORKSHOP CORPORATE SOCIAL RESPONSIBILITY AND LABOUR STANDARDS: Bridging Private Governance, Industrial Relations and Management Perspectives, 2015, Londres. Annals [...]. Londres, 2015. p. 23-24.

VIANA, Marco Túlio. Trabalho escravo e "lista suja": um modo original de se remover uma mancha. Rev. Trib.

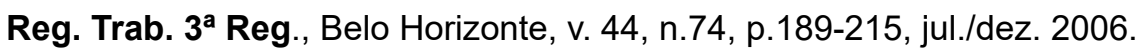

WOOD, Donna J. Corporate Social Performance Revisited. The Academy Management Review, New York, v. 16, n. 4, p. 691-718, out. 1991. Disponível em: https://www.jstor.org/stable/258977?seq=25\#metadata_info_tab_ contents. Acesso em: 03 jul. 2021.

Recebido em: 21.10 .2020

Aceito em: 18.06.2021 
O programa better work da oit e estratégias para a promoção do trabalho decente na cadeia produtiva do vestuário da cidade de Fortaleza: uma propostade adaptação para a realidade local 